\title{
Gold and Mössbauer Spectroscopy
}

\author{
THE USE OF GOLD-197 MÖSSBAUER SPECTROSCOPY TO CHARACTERIZE GOLD COMPOUNDS
}

\section{R. V. Parish}

Department of Chemistry, The University of Manchester Institute of Science and Technology, Manchester, U.K.

\begin{abstract}
Altbough Mössbauer spectroscopy bas been applied to characterizing compounds of gold for some time, it is only recently that its diagnostic value bas been fully appreciated. This article outlines the technique and shows bow the spectroscopic parameters depend systematically on the structures of the compounds. Recent examples are given in which oxidation states, coordination numbers, and structures bave been elucidated.
\end{abstract}

Mössbauer spectroscopy is a nuclear resonance technique which can be employed as a 'fingerprinting' method to determine the oxidation state or the chemical environment of particular atoms; it can also be used for more detailed studies of the distribution of electron densities. As with other nuclear techniques, only certain isotopes are suitable. Fortunately, the only naturally occurring gold isotope, gold-197, has favourable properties, and investigations with it have been carried out since the early days of the technique. The information obtainable from gold-197 Mössbauer spectra for gold compounds is reviewed below from the point of view of the empirical recognition of the oxidation state or coordination number of the metal and the nature of the groups chemically bonded to the gold atom. Examples are given of the application of the technique to systems which would be very difficult to characterize by other means.

\section{Mössbauer Spectroscopy}

The alternative name for Mössbauer spectroscopy, nuclear gamma resonance (NGR) spectroscopy, is the more descriptive. It indicates that the technique is essentially a branch of absorption spectroscopy in which gamma rays from a radioactive form of the isotope under study are used as the source of exciting radiation. Some general references to the technique are given in (1).

Since gamma sources are highly monochromatic, special arrangements are necessary to vary the energy of the radiation and so scan a spectrum. The normal procedure is to employ the Doppler effect: the source is given a velocity which results in a change in the frequency, and hence in the energy, of the radiation falling upon the sample:

$$
E_{\mathrm{\jmath}}=E(1+v / c)
$$

where

$E$ is the energy of the incident radiation

$E_{\mathrm{g}}$ is the gamma energy of the stationary source

$\nu$ is the applied velocity

$c$ is the velocity of light.
The energy range which it is necessary to scan is very small, and velocities of only a few millimetres per second are needed. For gold-197, $1 \mathrm{~mm} / \mathrm{s}$ corresponds to $2.6 \times 10^{-7} \mathrm{eV}$ (about $4 \times 10^{-12} \mathrm{~J}$ ). Data are normally quoted in velocity units without conversion to the more conventional form.

Gamma radiation is the result of an energy transition within the nucleus; the nucleus drops from an excited state to its ground state. When gamma rays are absorbed by the sample nuclei this process is reversed but, because the nuclear energy levels are sensitive to the electronic environment of the nucleus, the transition energy may not be identical to that of the source or of the incident radiation. Equivalence may be restored by applying an appropriate velocity to the source. Thus, the source is moved continuously through a range of velocities using an electromechanical vibrator fed with a suitable waveform, and the gamma radiation transmitted by the sample is monitored. At the critical velocity, the radiation is absorbed and the transmitted intensity falls, as in any other form of absorption spectroscopy. It is therefore necessary to record the gamma flux as a function of source velocity, and this is achieved by use of a multichannel analyzer. The channels are addressed successively, and the sweep through them is locked in phase with the vibrator drive waveform. Thus, each channel corresponds to a small section of the velocity range. The spectrum is scanned many times and the results accumulated until an adequate signal/noise ratio is achieved. (The signal increases in direct proportion to the number of scans but the noise, being random, is somewhat self-cancelling and increases only as the square-root of the number of scans.)

The final spectrum is obtained as a series of points representing the gamma-counts recorded at different velocities. Computer fitting of the data is usual, and iterative leastsquares methods are employed to fit a Lorentzian function to each absorption peak.

The excited state of the gold-197 nucleus required for the source has to be obtained indirectly, since it has a half-life of only $1.9 \times 10^{-9} \mathrm{~s}$. The usual approach is to irradiate a platinum foil in a nuclear reactor, causing the reaction 


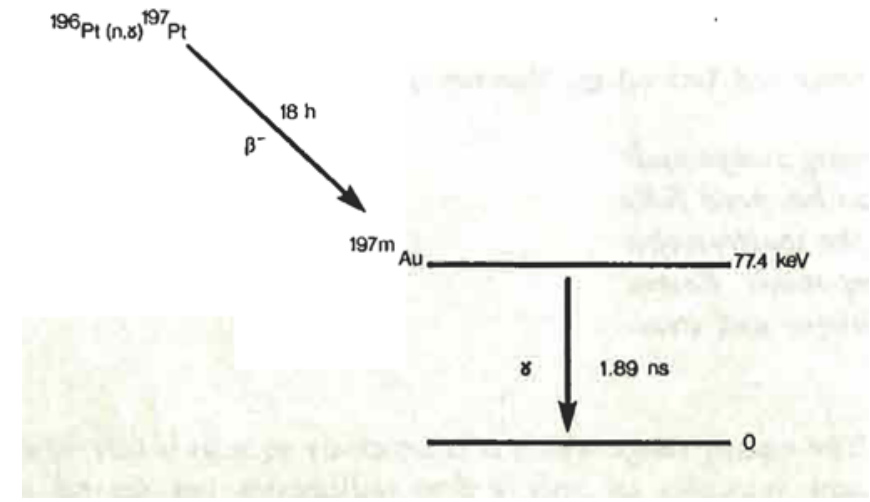

${ }^{196} \mathrm{Pt}[\mathrm{n}, \delta]{ }^{197} \mathrm{Pt}$

to occur, the product of which decays directly to the desired level of gold-197 (Figure 1). Unfortunately, the half-life of platinum-197 is $18 \mathrm{~h}$, so that a source can be used for only a few days, after which re-activation is necessary. Lengthy investigations therefore require close access to a nuclear reactor. Natural platinum (25 per cent platinum-196) can be used, but by-product isotopes give considerable quantities of unwanted radiation, which may saturate the gamma detector, and the use of enriched platinum-196 is therefore preferable to natural platinum.

Using normal counting systems, sources of practical strength (of the order of $0.5 \mathrm{mCi}$ ), and samples thin enough

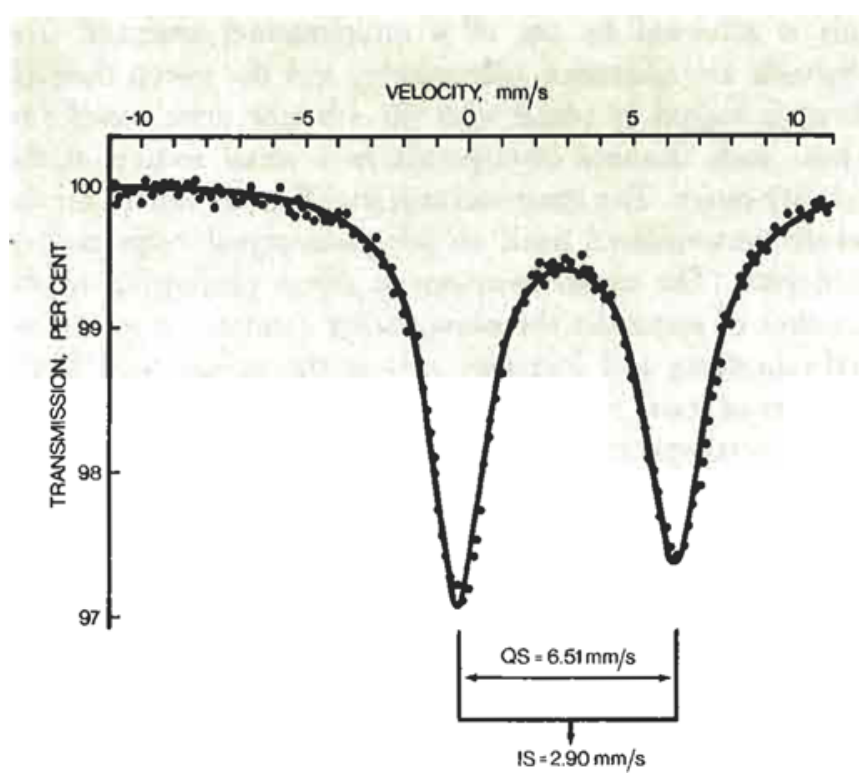

Fig. 1 Preparation and decay of platinum-197

ao give unbroadened absorption lines (that is, of the order of $\left.100 \mathrm{mg}(\mathrm{Au}) / \mathrm{cm}^{2}\right)$, well-defined spectra can be obtained in a few hours. A technique for integrating current has been described and this has been shown to drastically reduce this time (2).

One further disadvantage of the technique should also be mentioned. The emission or absorption of gamma rays makes the nucleus recoil and gain kinetic energy at the expense of the gamma photon, thus removing the possibility of resonant absorption. However, these processes are quantized and, in order that the overall recoil energy should match the weighted average of the quantized states, a certain fraction of nuclei must undergo no recoil at all. It is these recoil-free nuclei which give rise to the Mössbauer spectrum, and the recoil-free fraction decreases with increasing gamma energy and with increasing temperature. The gamma energy for gold-197 is relatively high and, consequently, low temperatures are required to obtain reasonably well-defined absorption spectra. It is usual to immerse both the source and the sample in liquid helium $(4.2 \mathrm{~K})$, a procedure which increases both the complexity of the equipment and the cost of obtaining spectra.

\section{The Mössbauer Parameters}

The majority of gold compounds give doublet spectra, a typical example of which is given in Figure 2. Such spectra are characterized by two major parameters:

(a) The isomer shift, IS, the position of the centroid of the doublet, is a measure of the total electron density at the gold nucleus. The IS arises because the nucleus increases in radius on absorption of a gamma photon. This results in an increase in the interaction with the local electron density and hence an increase in the transition energy. Since only $s$ electrons make direct contact with the nucleus, an increase in IS reflects principally an increase in the population of the valence shell $6 s$ orbital of the gold atom. Such a rise might be caused by, for instance, an increase in covalency in the bonds to neighbouring atoms. Increased populations of the $5 d$ or $6 p$ orbitals would give small negative contributions to the IS by increasing the

Fig. 2 Gold-197 Mössbauer spectrum of sodium gold thiomalate (MYOCRYSIN), illustrating the definition of isomer shift and quadrupole splitting. The solid line is the computer-fitted spectrum, consisting of two Lorentzian curves 
Fig. 3 The effect of (a) an electric-field gradient (EFG) $q$ and (b) a magnetic field $\mathrm{H}$ on the nuclear energy levels and the Mössbauer spectrum for gold-197

shielding of the nucleus from s electron density. Isomer shifts for gold compounds cover relatively large ranges, from about -0.5 to $+8 \mathrm{~mm} / \mathrm{s}$, measured relative to the single line resonance of elemental gold.

(b) The quadrupole splitting, QS, the separation between the two absorption peaks of the doublet, is a measure of the asymmetry of distribution of electronic charge about the gold nucleus, that is the difference in population between the $6 p_{z}$ orbital and the $6 p_{\mathrm{x}}$ and $6 p_{\mathrm{y}}$ orbitals (or between the $d$ orbitals). Intermetallic systems usually show zero or very small values of QS, consistent with the high symmetry of their structures, but gold(I) and gold(III) compounds show splittings of up to 12 and $9 \mathrm{~mm} / \mathrm{s}$ respectively. The higher values in each case are again associated with highly covalent systems. The effect arises because the ground-state gold-197 nucleus (spin $I=3 / 2$ ) possesses a quadrupole moment which interacts with an electric-field gradient, EFG, to give two energy levels and, hence, two transitions (Figure 3). An EFG arises whenever the gold atom occupies a site with less than cubic symmetry. This phenomenon is the same as that utilized in nuclear quadrupole resonance spectroscopy and the magnitude of the QS is one-half the quadrupole coupling constant:

$$
\mathrm{QS}=e^{2} q Q / 2
$$

For gold-197, a QS of $1 \mathrm{~mm} / \mathrm{s}$ corresponds to a quadrupole coupling constant of $125 \mathrm{mHz}$.

Taken together, the IS and QS are usually sufficient to distinguish and characterize gold(I) or gold(III) compounds, and to give a good indication of the number and types of ligands bound to the metal atom.

In alloys and intermetallic compounds, an additional effect may operate. In systems involving the transition metals there is often a strong internal magnetic field, the effect of which is to remove totally the degeneracy between the spin sub-states $\left(m_{1}\right.$ sublevels). The ground state splits into four sublevels and the excited state into two, and all eight possible transitions are allowed (Figure 3). (This would not normally be true, but is a result of the combined magnetic dipole (M1) and electric quadrupole (E2) interactions in gold-197.) For gold-197 the magnetic interaction is small compared with the line widths (typically about $1.9 \mathrm{~mm} / \mathrm{s}$ ) and well-resolved spectra can be seen only with fields greater than about $100 \mathrm{~T}(1000 \mathrm{kOe})$.

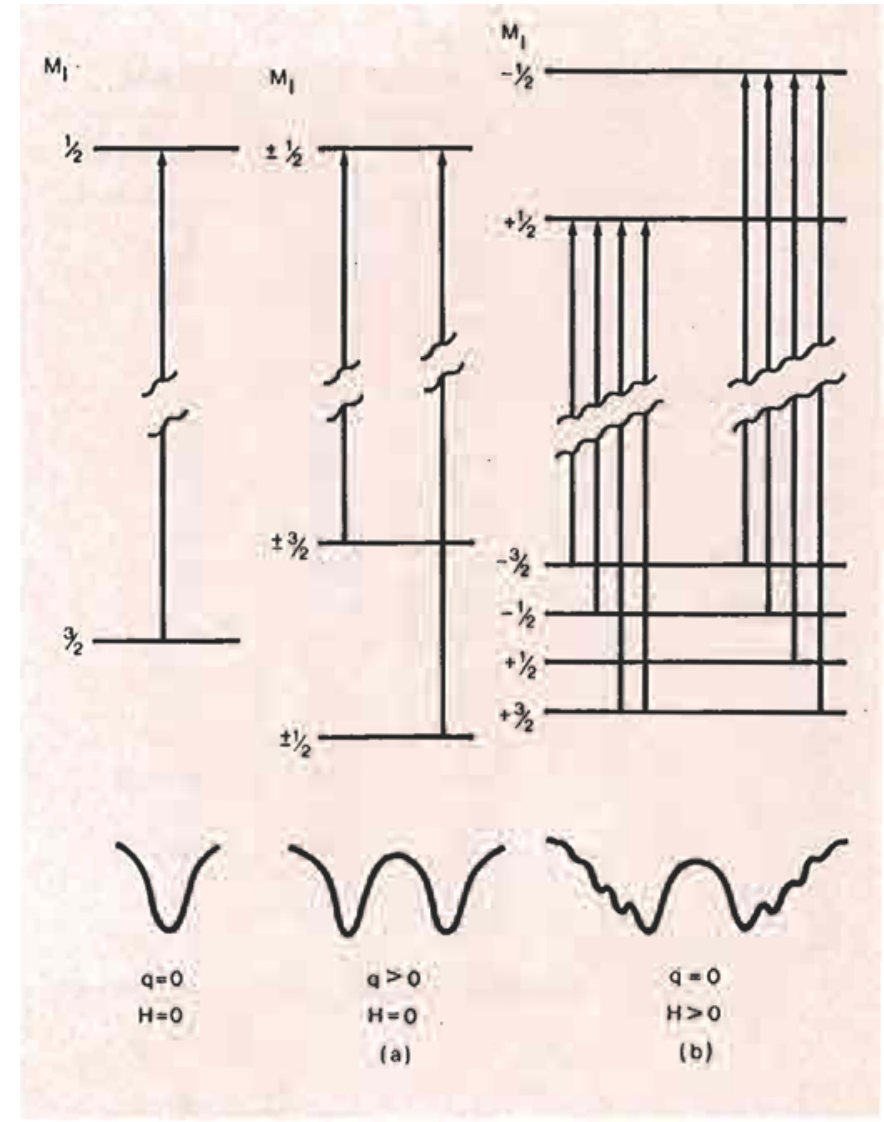

Gold(I)

\section{Two-Coordination}

In the vast majority of its compounds and coordination complexes, gold(I) is two-coordinate. In these systems there is a good correlation between the Mössbauer parameters and the nature of the ligands, which is a considerable aid to characterization. The gold atom has a $5 d^{10}$ configuration with $6 s 6 p$ hybridization. Thus; the IS and QS reflect directly the population of the $6 s$ and $6 p$ orbitals respectively, both of which increase as the ligands become better donors and the bonds more covalent. The lowest IS and QS values are found for the gold(I) halides. In these polymeric compounds the bridging halide ions may be considered as forming two coordinate bonds to two different gold cations. In $\left[\mathrm{AuX}_{2}\right]^{-}$each halide ion is bound to only one gold cation, and is able to donate more charge; the parameters being correspondingly greater. Progressively higher values of IS and QS are manifested as the ligand donor atom is changed from nitrogen to sulphur to phosphorus to carbon. This trend can be clearly seen in Table 1 shown below. 
Table I

Gold-197 Mössbauer Parameters for AuL 2 Systems

\begin{tabular}{|c|c|c|c|}
\hline Ligand L & $\begin{array}{c}\text { IS } \\
\mathrm{mm} / \mathrm{s}\end{array}$ & $\begin{array}{c}\mathrm{QS} \\
\mathrm{mm} / \mathrm{s}\end{array}$ & References * \\
\hline $1^{-}$ & 1.74 & 5.75 & 3,4 \\
\hline $\mathrm{Br}-$ & 1.66 & 6.35 & 3,4 \\
\hline $\mathrm{Cl}^{-=}$ & 1.84 & 6.28 & 3,4 \\
\hline $\mathrm{SPPh}_{3}$ & 2.46 & 6.82 & 3 \\
\hline $\mathrm{N}_{3}^{-}$ & 2.61 & 6.84 & 3 \\
\hline $\mathrm{S}: \mathrm{CNHCH}_{2} \mathrm{CH}_{2} \mathrm{NH}$ & 2.76 & 7.36 & 3 \\
\hline $\mathrm{S}_{2} \mathrm{O}_{3}^{2-}$ & 3.13 & 7.01 & 5 \\
\hline $\mathrm{NC}_{5} \mathrm{H}_{5}$ & 3.19 & 7.32 & 3 \\
\hline $\mathrm{SMe}_{2}$ & 3.43 & 7.56 & 3 \\
\hline $\mathrm{NHC}_{5} \mathrm{H}_{10}$ & 4.04 & 7.88 & 3 \\
\hline $\mathrm{AsPh}_{3}$ & 3.93 & 8.45 & 3 \\
\hline $\mathrm{AsMe}_{2} \mathrm{Ph}$ & 4.08 & 8.24 & 6 \\
\hline $\mathrm{CN}^{-}$ & 4.36 & 10.10 & $7-10$ \\
\hline $\mathrm{PMePh}_{2}$ & 4.89 & 9.35 & 3,11 \\
\hline $\mathrm{PEtPh}_{2}$ & 4.99 & 9.49 & 11 \\
\hline $\mathrm{PEt}_{2} \mathrm{Ph}$ & 4.93 & 9.77 & 11 \\
\hline $\mathrm{PPh}_{3}$ & 5.24 & 9.53 & $3,11,12$ \\
\hline $\mathrm{PMe}_{2} \mathrm{Ph}$ & 5.30 & 9.71 & 13 \\
\hline $\mathrm{PEt}_{3}$ & 5.40 & 10.18 & 3 \\
\hline $\mathrm{P}\left(\mathrm{C}_{5} \mathrm{H}_{11}\right)_{3}$ & 5.44 & 10.37 & 3 \\
\hline $\begin{array}{l}\mathrm{C}_{6} \mathrm{H}_{4} \mathrm{NMe}_{2}- \\
\text { - Relative to gold met }\end{array}$ & 6.86 & 12.01 & 14 \\
\hline
\end{tabular}

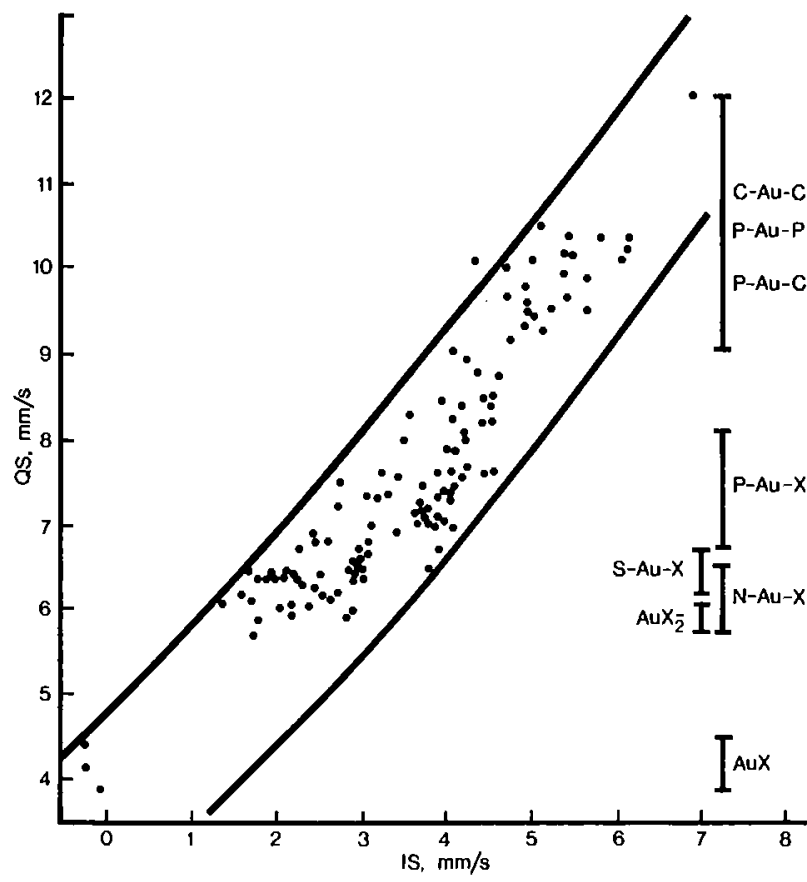

Fig. 4 QS-IS correlation diagram for two-coordinate gold(I), showing the ranges for different ligand systems
When all the available data are assembled on a graph of QS against IS (Figure 4), a good, effectively linear correlation is found between the two parameters. This suggests that the parameters for mixed-ligand complexes are the average of those for the two corresponding bis-ligand complexes. Thus, the data of Table I may be used to calculate values for mixedligand complexes, to give the results shown in Table II. Agreement with the experimental values is usually quite good, typical discrepancies being 0.3 to $0.5 \mathrm{~mm} / \mathrm{s}$ for IS and 0.5 to $0.7 \mathrm{~mm} / \mathrm{s}$ for QS. Since these variations are only 10 to 15 per cent of the actual values, the technique is both satisfactory and useful. The method is equivalent to the calculation of partial isomer shift and partial quadrupole splitting values for each ligand, which is described elsewhere $(3,6,11)$. The advantage of the latter method is that IS and QS values can be obtained for ligands for which data for the bis-ligand comple" $\mathrm{AuL}_{2}$ are not available.

Close inspection reveals that the differences between experimental and calculated data given in Table II are systematic. The averaging treatment overestimates the $Q S$ in every case and underestimates the IS in the majority of cases. This behaviour cannot be the result simply of the scatter of data, but must be more fundamental. The basic assumption made in the averaging treatment is that QS and IS are linearly related, that is that the hybridization of the gold atom is constant, and that the bond made by one ligand is independent of the identity of the second ligand. If the data of Table II are plotted, it will be seen that the correlation is not precisely linear but has a distinct positive curvature (concave upward). Thus, as the ligands become softer (less electronegative donor atoms), the QS increases proportionally more rapidly than the IS. Positive curvature would account for the signs of the discrepancies of intermediate values calculated by linear interpolation from the extremes. The different interdependence of QS and IS for different ligand systems can be illustrated in another way, which also provides a convenient means of evaluating Mössbauer data. In Figure 5 are shown QS-IS correlations for three systems:

(a) All compounds with at least one gold-halogen bond

(b) All those involving at least one gold-sulphur bond

(c) Those with at least one gold-phosphorus bond.

In each case a good correlation is achieved, but the slope increases dramatically as the constant ligand changes from halide to sulphur to phosphorus, that is, as the ligand becomes softer and the gold-ligand bond more covalent. This has been interpreted in terms of re-hybridization at the gold atom (3). According to Bent's rule, the greatest $s$ character is found in the bond to the least electronegative group, that is, in this context the softer ligand. Thus, in a basically $s p$ - 

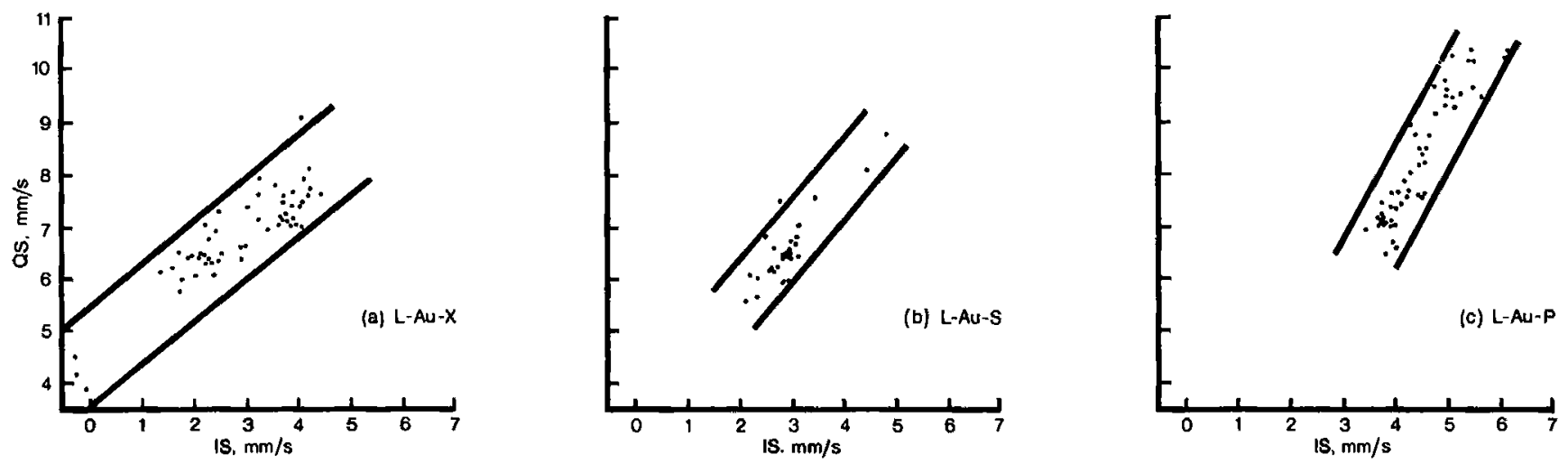

Fig. 5 QS-IS correlation diagram for two-coordinate gold(I) compounds containing (a) $\mathrm{Au}-\mathrm{X}$ bonds $(\mathrm{X}=\mathrm{Cl}, \mathrm{Br}, \mathrm{I})$, (b) Au-S bonds, and (c) Au-P bonds

hybridized system, the second gold-ligand bond must have correspondingly greater $6 p$ character. Under these circumstances, the second ligand donates more charge to the $6 p$ orbital and, hence, affects the QS more strongly than when the constant ligand is harder (more electronegative donor atoms).

Thus, in attempting to correlate data for a particular compound with other available data, comparison should be made with systems containing only one of the two ligands present in the compound under consideration. Greatest discrimination will probably be found if the softer ligand is chosen, since this ligand contributes the greater amount of charge. Thus, data for a phosphine complex $\left[A \mathrm{u}(\mathrm{Y})\left(\mathrm{PR}_{3}\right)\right](\mathrm{Y}=$ anion $)$ would be more usefully compared with data for other phosphine complexes than with those for Au-Y complexes. As illustrated below, deviations from these correlations are often associated with irregular structures.

\section{Higher Coordination Numbers}

In recent years, several examples of possible three- and four-coordination of gold(I) have been reported (a summary is given in (6)). With suitable ligands, confirmation of structures in solution can be achieved by phosphorus-31 NMR spectroscopy for example $(6,15$ to 18$)$. The determination of structures for solids is more difficult, especially when large organic ligands are involved, since it is by no means certain that all the ligand present in the solid is coordinated to the metal; equally, anions may or may not be coordinated. However, Mössbauer spectroscopy has proved invaluable in such cases.

Data for several potentially three-coordinate complexes are given in Table III. For the complexes [AuX(L) $](X=\mathrm{Xl}, \mathrm{I}$, SCN), the parameters for $\mathrm{L}=\mathrm{PEt}_{3}$ fit the two-coordination correlation quite well (Figure 6, points 9 and 10), but those for $\mathrm{L}=\mathrm{PPh}_{3}$ (points 3,4 and 5) lie well away to the low IS side. It seems likely that there is a structural difference between the two sets of complexes, and X-ray determinations have shown that in $\left[\mathrm{AuX}\left(\mathrm{PPh}_{3}\right)_{2}\right](\mathrm{X}=\mathrm{Cl}, \mathrm{I})$ the gold is
Table II

Calculated and Experimental IS and OS Values

\begin{tabular}{|c|c|c|c|c|c|c|}
\hline \multirow[t]{2}{*}{ Compound } & \multicolumn{3}{|c|}{$\begin{array}{c}\mathrm{IS}, \\
\mathrm{mm} / \mathrm{s}\end{array}$} & \multicolumn{3}{|c|}{$\begin{array}{c}\mathrm{QS}, \\
\mathrm{mm} / \mathrm{s}\end{array}$} \\
\hline & Calc. & Exp. & Diff. & Caic. & Exp. & Diff. \\
\hline $\mathrm{AuCl}\left(\mathrm{PPh}_{3}\right)$ & 3.54 & 4.08 & -0.54 & 7.90 & 7.43 & +0.47 \\
\hline Aul $\left(\mathrm{PPh}_{3}\right)$ & 3.49 & 4.03 & -0.54 & 8.12 & 7.36 & +0.76 \\
\hline $\mathrm{Au}(\mathrm{CN})\left(\mathrm{PPh}_{3}\right)$ & 4.80 & 5.07 & -0.27 & 10.31 & 10.25 & +0.05 \\
\hline$\left[\mathrm{Au}\left(\mathrm{NC}_{5} \mathrm{H}_{5}\right) \mathrm{PPh}_{3}\right]^{+}$ & 4.22 & 4.55 & -0.33 & 8.90 & 8.50 & +0.40 \\
\hline$\left[\mathrm{Au}\left(\mathrm{SMe}_{2}\right)\left(\mathrm{PPh}_{3}\right]^{+}\right.$ & 4.34 & 4.44 & -0.10 & 9.02 & 8.20 & +0.82 \\
\hline AuCl $\left(\mathrm{NC}_{5} \mathrm{H}_{5}\right)$ & 2.52 & 2.29 & +0.23 & 6.80 & 6.75 & +0.05 \\
\hline $\mathrm{AuCl}\left(\mathrm{SMe}_{2}\right)$ & 2.64 & 2.38 & +0.26 & 6.92 & 6.05 & +0.87 \\
\hline $\mathrm{AuCl}\left(\mathrm{PMePh}_{2}\right)$ & 3.37 & 3.65 & -0.28 & 7.82 & 7.02 & +0.80 \\
\hline $\mathrm{AuCl}\left(\mathrm{PMe} \mathrm{P}_{2} \mathrm{Ph}\right)$ & 3.57 & 3.91 & -0.34 & 8.00 & 7.11 & +0.89 \\
\hline $\mathrm{AuCl}\left(\mathrm{PEt}_{3}\right)$ & 3.62 & 3.78 & -0.16 & 8.24 & 7.08 & +1.16 \\
\hline $\mathrm{AuCl}\left(\mathrm{Pcy}_{3}\right)^{*}$ & 3.64 & 4.43 & -0.79 & 8.32 & 7.59 & +0.73 \\
\hline $\mathrm{AuBr}\left(\mathrm{Pcy}_{3}\right)^{*}$ & 3.55 & 4.19 & -0.64 & 8.36 & 7.56 & +0.80 \\
\hline
\end{tabular}


Table III

Mössbauer Data for Possible Three-Coordinate Gold(I) Complexes

\begin{tabular}{|c|c|c|c|c|}
\hline Compound & $\begin{array}{c}\text { IS, } \\
\mathrm{mm} / \mathrm{s}\end{array}$ & $\begin{array}{c}\text { QS, } \\
\mathrm{mm} / \mathrm{s}\end{array}$ & $\begin{array}{c}\text { Number of } \\
\text { point in } \\
\text { Figure } 6\end{array}$ & Refs. \\
\hline $\mathrm{AuCl}\left(\mathrm{PEt}_{3}\right)_{2}$ & 4.25 & 8.93 & 9 & 19 \\
\hline Aul $\left(\mathrm{PEt}_{3}\right)_{2}$ & 4.38 & 8.79 & 10 & 19 \\
\hline $\mathrm{AuCl}\left(\mathrm{PPh}_{3}\right)_{2}$ & 2.35 & 8.22 & 4 & $6,11,19$ \\
\hline $\mathrm{Aul}\left(\mathrm{PPh}_{3}\right)_{2}$ & 2.62 & 7.98 & 5 & 6,19 \\
\hline $\mathrm{Au}(\mathrm{SCN})\left(\mathrm{PPh}_{3}\right)_{2}$ & 2.46 & 8.52 & 3 & 19 \\
\hline$\left[\mathrm{MeN}\left(\mathrm{PPh}_{2}\right)_{2} \mathrm{AuCl}\right]_{2}$ & 2.23 & 7.04 & 11 & 20 \\
\hline$\left[\mathrm{Au}\left(\mathrm{PPh}_{3}\right)_{3}\right] \mathrm{ClO}_{4}$ & 2.99 & 9.47 & 2 & 12 \\
\hline$\left[\mathrm{Au}\left(\mathrm{Ptol}_{3}\right)_{3}\right] \mathrm{ClO}_{4}{ }^{\circ}$ & 2.99 & 9.74 & 1 & 6 \\
\hline [Au (bipy) $\left.\left(\mathrm{PEt}_{3}\right)\right] \mathrm{PF}_{6}$ & 2.96 & 7.33 & 6 & 19 \\
\hline$\left[\mathrm{Au}\right.$ (bipy) $\left.\left(\mathrm{PPh}_{3}\right)\right] \mathrm{PF}_{6}$ & 2.81 & 6.76 & 8 & 19 \\
\hline$\left[\mathrm{Au}\right.$ (phen) $\left.\left(\mathrm{PPh}_{3}\right)\right] \mathrm{PF}_{6}$ & 2.82 & 7.05 & 7 & 19 \\
\hline it - - ntolut & & & & \\
\hline
\end{tabular}

three-coordinate $(21,22)$. The $\mathrm{PEt}_{3}$ complexes are presumably ionic with two-coordinate gold, $\left[\mathrm{Au}\left(\mathrm{PEt}_{3}\right)_{2}\right] \mathrm{X}$, as are the $\mathrm{PPh}_{3}$ complexes in solution. The two compounds $\left[\mathrm{Au}\left(\mathrm{PR}_{3}\right)_{3}\right] \mathrm{ClO}_{4}(\mathrm{R}=\mathrm{Ph}, p$-tolyl $)$ show a similar deviation from the two-coordination correlation (Figure 6 , points 1 and 2 ) and presumably also contain three-coordinate gold. This is consistent with phosphorus-31 NMR data $(17,18)$, and $\left[\mathrm{Au}\left(\mathrm{PPh}_{3}\right)_{3}\right]+$ has been identified by X-ray crystallography in the $\mathrm{BPh}_{4}-$ and $\mathrm{B}_{9} \mathrm{H}_{12} \mathrm{~S}-$ salts $(23,24)$.

The data for the complexes with the potentially bidentate ligands 2,2'-bipyridyl and $o$-phenanthroline are more

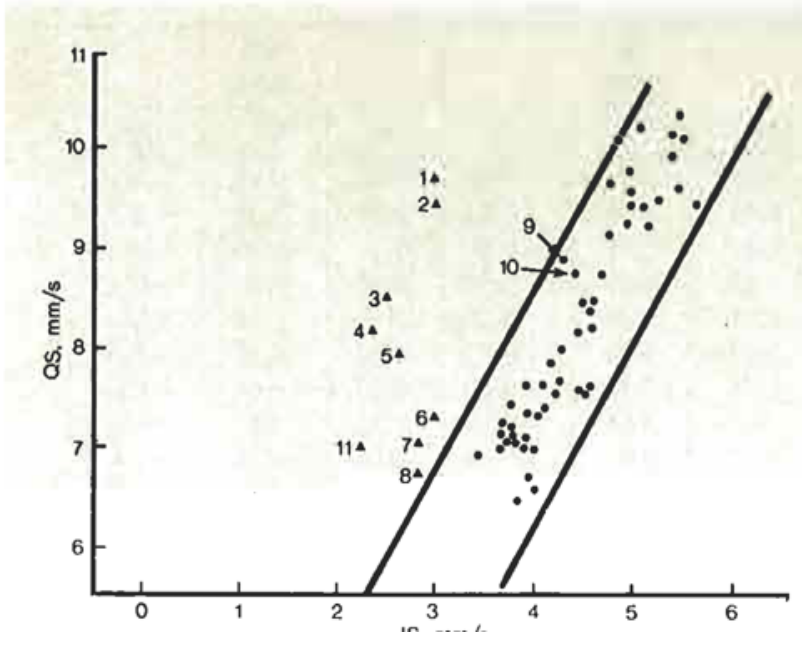

difficult to assess. In Figure 6 (points 6,7 and 8), these data lie slightly to the low IS side of the main band of values, suggesting possible three-coordination for the gold. However, if the data are compared with those for complexes containing a Au-N bond, no such discrepancy is found. This ambiguity is a reflection of the structural characteristics: $\mathrm{X}$-ray crystallography (25) shows that the gold atom in [Au(bipy) $\left.\left(\mathrm{PPh}_{3}\right)\right] \mathrm{PF}_{6}$ has very irregular planar coordination with two distinct $\mathrm{Au}-\mathrm{N}$ bond lengths (217 and $241 \mathrm{pm}$ ). The shorter bond makes an angle of $157^{\circ}$ with the Au-P bond, and the latter bond is actually shorter than those in many two-coordinate complexes. The structure is thus considered to be intermediate between those represented by two- and three-coordination.

Several complexes of the type $\left[\mathrm{Au}(\mathrm{L})_{4}\right] \mathrm{ClO}_{4}$ have been reported $(6,12,13)$ and are shown in Table IV. All give sharp single-line spectra, that is, the $Q S$ is zero. Such a value unambiguously demonstrates tetrahedral four-coordination for the gold. Tetrahedral $\left(T_{d}\right)$ symmetry results in a zero EFG regardless of the identity of the four ligands, requiring only that they be identical. The IS values of these complexes reflect the expected donor ability of the ligands, increasing from $\mathrm{AsPh}_{3}$ to $\mathrm{PPh}_{3}$ to $\mathrm{PPh}_{2} \mathrm{Me}$ and to $\mathrm{PPhMe}_{2}$. The complex $\left[\mathrm{Au}\left(\mathrm{SnCl}_{3}\right)\left(\mathrm{PPh}_{3}\right)_{3}\right]$ has very different Mössbauer parameters from those of $\left[\mathrm{Au}\left(\mathrm{PPh}_{3}\right)_{3}\right] \mathrm{ClO}_{4}$, which implies that the $\mathrm{SnCl}_{3}{ }^{-}$ion is coordinated to the gold. The low values of both parameters are consistent with four-coordination, and the tin-119 Mössbauer spectrum also indicates a gold-tin interaction (26).

The four-coordinate complexes are also characterized by very low IS values. There is a progressive and substantial decrease in IS as the coordination number increases. This phenomenon is observed with other isotopes, but is particularly pronounced for gold-197, partly as a result of favourable nuclear parameters (the gold-197 nucleus undergoes a large change in radius on excitation). Further enhancement of the effect occurs because the coordination numbers are low. The IS reflects the electron density at the nucleus, which is due to $s$ electrons. As the coordination number increases, the hybridization of the gold atom changes from $s p$ to $s p^{2}$ to $s p^{3}$. The resulting large percentage increase in population of the $6 p$ orbitals changes the shielding of the nucleus from the $s$ electrons and, as a consequence produces a decrease in IS. 


\begin{tabular}{|c|c|c|c|}
\hline \multicolumn{4}{|c|}{$\begin{array}{l}\text { Table IV } \\
\text { Mössbauer Data for Four-Coordinate } \\
\text { Gold (I) Complexes }\end{array}$} \\
\hline Compound & $\begin{array}{l}\text { IS, } \\
\mathrm{mm} / \mathrm{s}\end{array}$ & $\begin{array}{l}\text { QS, } \\
\mathrm{mm} / \mathrm{s}\end{array}$ & Reference \\
\hline $\begin{array}{l}{\left[\mathrm{Au}\left(\mathrm{AsPh}_{3}\right)_{4}\right] \mathrm{ClO}_{4}} \\
{\left[\mathrm{Au}\left(\mathrm{PPh}_{3}\right)_{4}\right] \mathrm{ClO}_{4}} \\
{\left[\mathrm{Au}\left(\mathrm{PMePh}_{2}\right)_{4} \mathrm{ClO}_{4}\right.} \\
{\left[\mathrm{Au}\left(\mathrm{PMe}_{2} \mathrm{Ph}\right)_{4}\right] \mathrm{ClO}_{4}} \\
{\left[\mathrm{Au}\left(\mathrm{SnCl}_{3}\right)\left(\mathrm{PPh}_{3}\right)_{3}\right]}\end{array}$ & $\begin{array}{r}-0.39 \\
-0.17 \\
1.48 \\
1.98 \\
1.64\end{array}$ & $\begin{array}{l}0.00 \\
0.00 \\
0.00 \\
0.00 \\
3.57\end{array}$ & $\begin{array}{r}6 \\
12 \\
6 \\
13 \\
19\end{array}$ \\
\hline
\end{tabular}

It has been shown that the QS values for two- and threecoordinate complexes involving the same ligand should be approximately equal $(6,12)$ :

$$
\mathrm{QS}\left[\mathrm{AuL}_{2}\right] \approx \mathrm{QS}\left[\mathrm{AuL}_{3}\right]
$$

This is well borne out by data for $\mathrm{L}=\mathrm{PPh}_{3}$ or $\mathrm{P}(\text { tolyl })_{3}$ (Tables II and IV). Using the partial-quadrupole-splitting approach, it is also possible to calculate QS values for mixedligand three-coordinate systems which agree well with those observed (6). Thus, confirmation of both the coordination number and the identity of the ligands can be readily obtained.

\section{Gold(III)}

Fewer Mössbauer measurements have been made for gold(III) than for gold(I) compounds. Nevertheless, it is clear that the same general trends are shown by the two systems. The available data are plotted in Figure 7, which shows an approximately linear, positive correlation between QS and IS, with both values increasing as the ligands become softer. The coordination number is known, or may reasonably be assumed, to be four in all cases. Representative data are given in Table V. Additivity of ligand contributions probably applies to both. parameters, for example data for $\left[\mathrm{Au}(\mathrm{CN})_{2} \mathrm{X}_{2}\right]^{-}(\mathrm{X}=\mathrm{Cl}, \mathrm{Br})$ lie roughly mid-way between those for $\left[\mathrm{Au}(\mathrm{CN})_{4}\right]^{-}$and $\left[\mathrm{AuX}_{4}\right]^{-}$(Table VI). Insufficient data are available as yet, however, to make this a useful means of analysis. Notwithstanding this, it is apparent that, as with gold(I), the position of a datum point within the QS-IS correlation gives a good indication of the types of ligand involved.

Figure 8 shows the ranges of data for four-coordinate gold(III) and two-coordinate gold(I) plotted together. It is immediately apparent that, despite the scatter, the two oxidation states can be readily distinguished. For comparable sets of ligands, the IS values are similar but the QS is markedly smaller for gold(III). This effect arises from the $d^{t}$ con-
Table V

Mössbauer Data for Gold(III) Compounds

\begin{tabular}{|c|c|c|c|}
\hline Compound & $\begin{array}{c}\text { IS, } \\
\mathrm{mm} / \mathrm{s}\end{array}$ & $\begin{array}{c}\text { QS, } \\
\mathrm{mm} / \mathrm{s}\end{array}$ & References \\
\hline $\mathrm{AuF}_{3}$ & 0.14 & $(-) 2.74$ & 7 \\
\hline $\mathrm{AuCl}_{3}$ & 0.64 & $(-) 0.76$ & 7 \\
\hline $\mathrm{AuBr}_{3}$ & 0.42 & $(-) 1.27$ & 7 \\
\hline $\mathrm{Rb}\left[\mathrm{AuF}_{4}\right]$ & 1.26 & 0.17 & 8 \\
\hline $\left.\mathrm{Bu}_{4} \mathrm{~N}[\mathrm{AuCl}]_{4}\right]$ & 2.23 & 1.31 & 4 \\
\hline $\mathrm{Bu}_{4} \mathrm{~N}\left[\mathrm{AuBr}_{4}\right]$ & 2.13 & 1.50 & 4 \\
\hline $\left.\mathrm{K}[\mathrm{AuI})_{4}\right]$ & 1.64 & 1.28 & 8 \\
\hline $\mathrm{K}\left[\mathrm{Au}(\mathrm{SCN})_{4}\right]$ & 2.84 & 2.04 & 8 \\
\hline $\mathrm{AuBr}_{2}\left(\mathrm{~S}_{2} \mathrm{CNBu}_{2}\right)$ & 2.68 & 2.20 & 4 \\
\hline $\mathrm{AuBr}\left(\mathrm{S}_{2} \mathrm{CNBu}_{2}\right)_{2}$ & 3.44 & 2.80 & 4 \\
\hline $\mathrm{Bu}_{4} \mathrm{~N}\left[\mathrm{Au}(\mathrm{mnt})_{2}\right]$ & 4,13 & 2.33 & 4 \\
\hline $\mathrm{Bu}_{4} \mathrm{~N}\left[\mathrm{Au}(\mathrm{tdt})_{2}\right]^{*}$ & 4.20 & 2.73 & 4 \\
\hline $\mathrm{K}\left[\mathrm{A} u(\mathrm{CN})_{4}\right]$ & 5.4 & 6.9 & 7,8 \\
\hline $\mathrm{AuMe}_{2}\left(\mathrm{~S}_{2} \mathrm{CNBU}_{2}\right)$ & 5.20 & 5.11 & 4 \\
\hline$\left[\mathrm{AuMe}{ }_{2}(\mu-\mathrm{SMe})_{2}\right]_{2}$ & 5.09 & 5.04 & 27 \\
\hline$\left[\mathrm{AuMe}{ }_{2}(\mu-\mathrm{SeMe})\right]_{2}$ & 5.07 & 4.42 & 27 \\
\hline $\mathrm{AuMe}_{2} \mathrm{Cl}\left(\mathrm{PPh}_{3}\right)$ & 5.28 & 6.32 & 27 \\
\hline $\mathrm{AuMe}_{2} \mathrm{Cl}\left(\mathrm{PMePh}_{2}\right)$ & 5.27 & 6.33 & 27 \\
\hline $\mathrm{AuMe}_{2} \mathrm{Br}\left(\mathrm{PPh}_{3}\right)$ & 5.38 & 6.30 & 27 \\
\hline $\mathrm{AuMe}_{3}\left(\mathrm{PPh}_{3}\right)$ & 5.91 & 8.87 & 27 \\
\hline $\mathrm{AuMe}_{3}\left(\mathrm{PMePh}_{2}\right)$ & 5.87 & 8.76 & 28 \\
\hline \multicolumn{4}{|c|}{$\begin{array}{l}\mathrm{mnt}=\text { maleonitriledithiolate } \\
\because \mathrm{tt}=\text { toluenedithiolate }\end{array}$} \\
\hline . & & & \\
\hline
\end{tabular}

figuration of gold(III) coupled with the planar geometry of the compounds. In contrast to gold(I), there is now a contribution to the EFG from the valence shell of the gold atom in addition to that from the metal-ligand bonds. The eight $d$ electrons occupy the $d_{x y}, d_{x z}, d_{y z}$, and $d_{z^{2}}$ orbitals. The first three of these together constitute a sub-group with cubic

\begin{tabular}{|c|c|c|c|}
\hline \multicolumn{4}{|c|}{$\begin{array}{l}\text { Table VI } \\
\text { Mössbauer Data for Halide and } \\
\text { Cyanide Complexes of Gold(III) }\end{array}$} \\
\hline Compound & $\begin{array}{l}\text { IS, } \\
\mathrm{mm} / \mathrm{s}\end{array}$ & $\begin{array}{l}\text { QS, } \\
\mathrm{mm} / \mathrm{s} \text {. }\end{array}$ & References \\
\hline $\mathrm{K}\left[\mathrm{Au}(\mathrm{CN})_{4}\right]$ & 5.4 & 6.9 & 7,8 \\
\hline $\mathrm{K}\left[\left.\mathrm{Au}(\mathrm{CN})_{2}\right|_{2}\right]$ & 3.99 & 5.37 & 7 \\
\hline $\mathrm{K}\left[\mathrm{Au}(\mathrm{CN})_{2} \mathrm{Br}_{2}\right]$ & $3.90^{\circ}$ & 5.40 & 7,8 \\
\hline $\mathrm{K}\left[\mathrm{Au}(\mathrm{CN})_{2} \mathrm{Cl}_{2}\right]$ & 3.77 & 5.26 & 7 \\
\hline $\mathrm{K}\left[\mathrm{AuI}{ }_{4}\right]^{\circ}$ & 1.64 & 1.28 & 8 \\
\hline $\mathrm{K}\left[\mathrm{AuBr}{ }_{4}\right]^{*}$ & 1.86 & 1.2 & $4,7,8$ \\
\hline $\left.\mathrm{K}[\mathrm{AuCl}]_{4}\right]^{*}$ & 2.05 & 1.26 & 4,8 \\
\hline \multicolumn{4}{|c|}{$\begin{array}{l}\text { Includes hydrates. If other cations are included, a wide range of } \\
\text { values is found }\end{array}$} \\
\hline
\end{tabular}




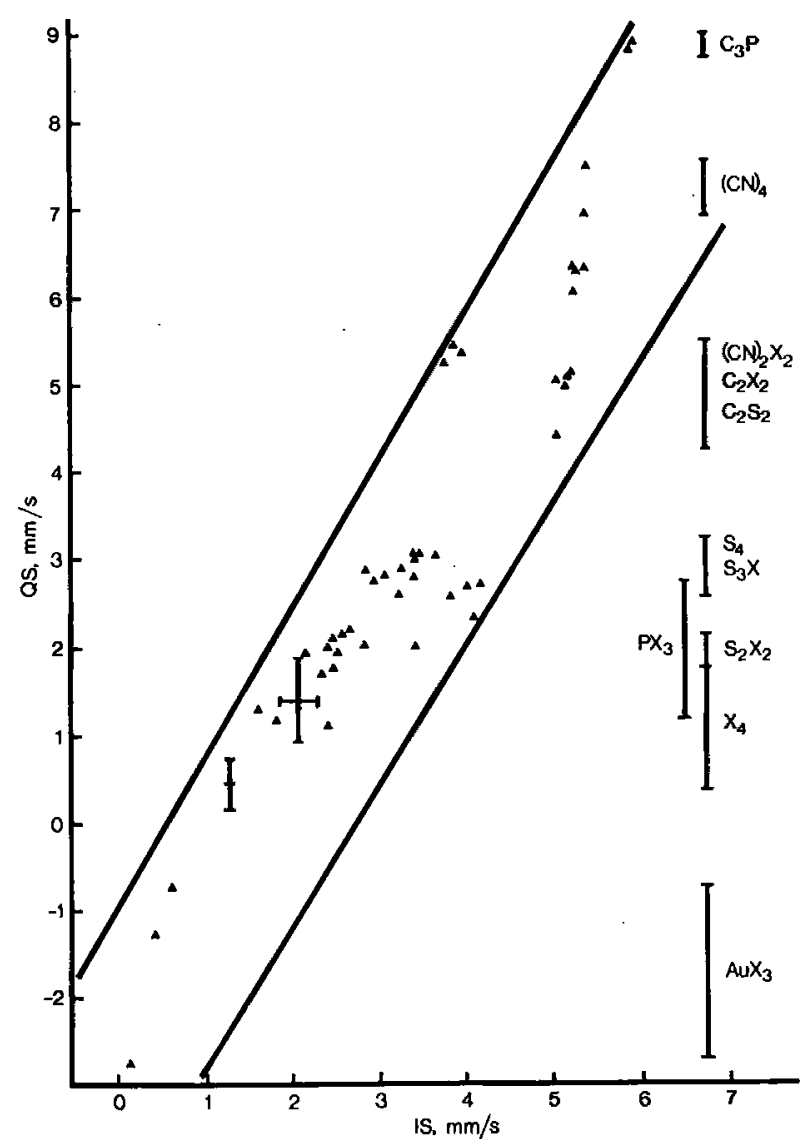

Fig. 7 QS-IS correlation diagram for gold(III), showing the regions corresponding to different donor atom sets. The two large crosses represent the ranges of data reported for $\left[\mathrm{AuCI}_{4}\right]^{-}$and $\left[\mathrm{AuF}_{4}\right]^{-}$

symmetry, and do not contribute to the EFG. However, the pair of electrons in the $d_{z^{2}}$ orbital makes a contribution opposite in sign to that from the electron density in the $x-y$ plane due to the gold-ligand bonds. This partial cancellation of the bond-EFG results in a smaller QS for gold(III) systems. The systematic increase in QS with increasing covalency indicates that the contribution from the bonding electrons outweighs that from the $5 d_{z^{2}}$ electrons in all cases except the gold trihalides $\mathrm{AuX}_{3}$. For this reason, the QS data for the trihalides are shown as negative. (The QS, being simply the peak separation, does not have a sign, but the arguments given above show that the EFG's for two-coordinate gold(I) and foukcoordinate gold(III) should be opposite in sign. This has been confirmed for the cyano-complexes: in $\left[\left(\mathrm{Au}(\mathrm{CN})_{2}\right]^{-}\right.$the EFG is negative (29), while that for $\left[\mathrm{Au}(\mathrm{CN})_{4}\right]^{-}$is positive (30).) Since gold(III) might be ex-

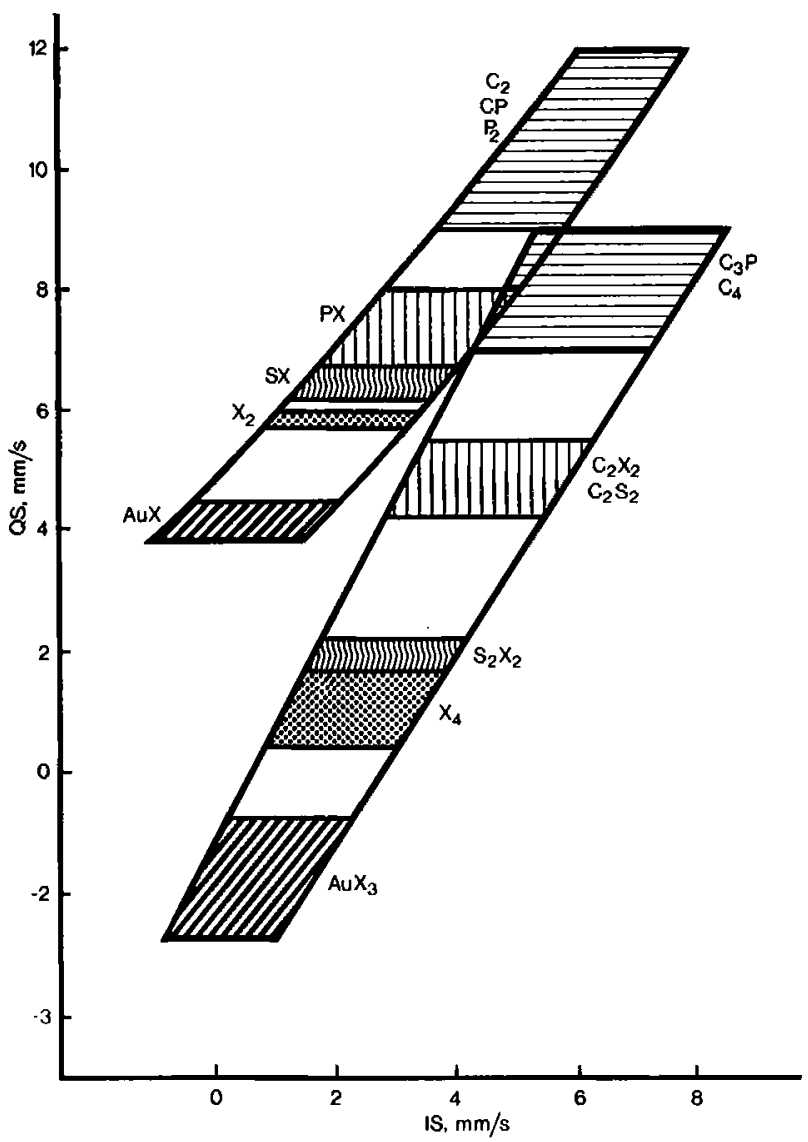

Fig 8. Comparison between gold(I) and gold(III) QS-IS correlation diagrams pected to be a better acceptor of charge from the ligands than gold(I), it might also be expected that both the IS and the QS would show greater variation for the higher oxidation state. Figure 8 shows that the QS range is indeed greater for gold(III) but, for similar ligands, the IS ranges are comparable for the two oxidation states. Gold(III) has $d s p^{2}$ hybridization and the populations of these hybrid orbitals increase as the ligands become softer. Change in population of the $6 s$ orbital has no direct effect on the QS, which therefore responds to the increasing populations of the $5 d_{x^{2}}-y^{2}, 6 p_{x}$ and $6 p_{y}$ orbitals; the contribution of the $5 d_{z^{2}}$ electron pair remains roughly constant. The change in population of the $6 s$ orbital causes an increase in the IS, but this is offset by the shielding effect of the rising $5 d$ and $6 p$ populations. The IS is thus less sensitive to change of ligand than the QS.

The data for the salts of $\left[\mathrm{AuX}_{4}\right]$ - anions $(\mathrm{X}=$ halogen $)$ 
show considerable dependence on the cation. For instance, for $\mathrm{X}=\mathrm{Cl}$, the IS varies from $1.87 \mathrm{~mm} / \mathrm{s}$ for the free acid $\mathrm{H}\left[\mathrm{AuCl}_{4}\right] .4 \mathrm{H}_{2} \mathrm{O}(28)$, to $2.30 \mathrm{~mm} / \mathrm{s}$ for the $\mathrm{AsPh}_{4}+$ salt (4); the QS also shows wide variation, from 0.94 to $1.88 \mathrm{~mm} / \mathrm{s}$. These variations presumably represent the polarizing effect of the cations. The general trend is for both parameters to increase as the cation becomes larger and less polarizing.

\section{Gold(II)}

Very few genuine gold(II) compounds are known. Many compounds which apparently contain gold(II) are actually mixed-valence (I plus III) systems which are readily recognized by their Mössbauer spectra (see below). Most of the other examples of gold in formal oxidation state + II are binuclear compounds in which two gold atoms are directly bonded together as in the following $(20,31,32)$ :
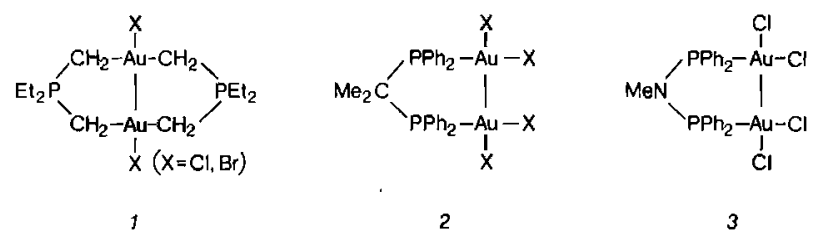

These compounds are obtained by the cautious oxidation of the corresponding gold(I) compounds, and are readily oxidized to gold(III):

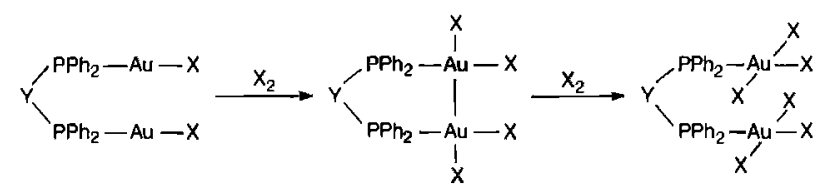

The Mössbauer data for the gold(II) compounds lie between those for the corresponding gold(I) and gold(III) derivatives (Table VII). In each case, however, the parameters are much closer to those of the gold(III) complexes, and lie within the normal range for gold(III) compounds. Electron spectroscopy for chemical analysis (ESCA) data also suggest that the charge on the gold(II) atoms is very similar to that in typical gold(III) compounds. These observations agree with the structures; since each gold atom is covalently bonded to another gold atom, it in fact forms a total of three covalent bonds and one coordinate bond. The gold is thus effectively trivalent and four-coordinate. The replacement of a goldhalogen bond in $\left.\mathrm{Y}\left(\mathrm{PPh}_{2} \mathrm{AuX}\right)_{3}\right)_{2}$ by a more covalent gold-gold bond in $\mathrm{Y}\left(\mathrm{PPh}_{2} \mathrm{AuX}_{2}\right)_{2}$ results in the normal rise in both IS and QS.

The paramagnetic gold(II) compound $\left(\mathrm{Bu}_{4} \mathrm{~N}\right)_{2}\left[\mathrm{Au}(\mathrm{mnt})_{2}\right]$ in which $\mathrm{mnt}=$ the maleonitriledithiolate anion, $-\mathrm{S}(\mathrm{NC}) \mathrm{C}=\mathrm{C}(\mathrm{CN}) \mathrm{S}-$, gives a complex Mössbauer spectrum
Table VII

Mössbauer and ESCA Data for Gold(I), Gold(II) and Gold(III) Complexes

\begin{tabular}{|c|c|c|c|c|}
\hline Compound & $\begin{array}{c}\mathrm{IS}, \\
\mathrm{mm} / \mathrm{s}\end{array}$ & $\begin{array}{c}\mathrm{QS}, \\
\mathrm{mm} / \mathrm{s}\end{array}$ & $\begin{array}{c}\mathrm{BE}\left[\mathrm{Au}\left(4 f_{7 / 2}\right)\right] \\
\mathrm{eV}\end{array}$ & Reference \\
\hline $\mathrm{MeN}\left(\mathrm{PPh}_{2} \mathrm{Au}^{\prime} \mathrm{Cl}\right)_{2}$ & 4.47 & 7.59 & & 20 \\
\hline $\mathrm{MeN}\left(\mathrm{PPh}_{2} \mathrm{Au}^{\prime \prime} \mathrm{Cl}_{2}\right)_{2}$ & 3.36 & 4.20 & & 20 \\
\hline $\left.\mathrm{MeN}\left(\mathrm{PPh}_{2} \mathrm{Au}^{\prime \prime \prime} \mathrm{Cl}\right)_{3}\right)_{2}$ & 2.95 & 2.45 & & 20 \\
\hline$\left[\mathrm{Et}_{2} \mathrm{P}\left(\mathrm{CH}_{2}\right)_{2} \mathrm{Au}^{\prime}\right]_{2}$ & 4.97 & 9.60 & 84.4 & 32 \\
\hline$\left[\mathrm{Et}_{2} \mathrm{P}\left(\mathrm{CH}_{2}\right)_{2} \mathrm{Au}^{\prime \prime} \mathrm{Br}\right]_{2}$ & 3.88 & 6.71 & 86.4 & 32 \\
\hline$\left[\mathrm{Et}_{2} \mathrm{P}\left(\mathrm{CH}_{2}\right)_{2} \mathrm{Au}^{\prime \prime \prime} \mathrm{Br}_{2}\right]_{2}$ & 3.23 & 5.52 & 87.0 & 31 \\
\hline $\mathrm{Me}_{2} \mathrm{C}\left(\mathrm{PPh}_{2} \mathrm{Au} \mathrm{u}^{\prime} \mathrm{Cl}\right)_{2}$ & 3.66 & 6.90 & 84.4 & 31 \\
\hline $\mathrm{Me}_{2} \mathrm{C}\left(\mathrm{PPh}_{2} \mathrm{Au}^{\prime \prime} \mathrm{Cl}\right)_{2}$ & 3.32 & 3.70 & 85.7 & 31 \\
\hline $\mathrm{Me}_{2} \mathrm{C}\left(\mathrm{PPh}_{2} \mathrm{Au}^{\prime \prime} \mathrm{ClBr}\right)_{2}$ & 3.22 & 3.58 & & 31 \\
\hline $\mathrm{Me}_{2} \mathrm{C}\left(\mathrm{PPh}_{2} \mathrm{Au}^{\prime \prime \prime} \mathrm{Cl}_{3}\right)_{2}$ & 2.41 & 2.00 & & 31 \\
\hline $\mathrm{H}_{2} \mathrm{C}\left(\mathrm{PPh}_{2} \mathrm{Au}^{\prime} \mathrm{Cl}\right)_{2}$ & 3.75 & 7.17 & 84.6 & 31 \\
\hline$\left(\mathrm{PPh}_{2} \mathrm{Au}^{\prime} \mathrm{Cl}\right)$ & 3.93 & 7.32 & 84.5 & \\
\hline$\left(\mathrm{PPh}_{2} \mathrm{Au}^{\prime \prime \prime} \mathrm{ClBr} \mathrm{Br}_{2}\right)$ & 3.09 & 2.81 & 86.4 & \\
\hline $\left.\mathrm{H}_{2}\left(\mathrm{PPh}_{2} \mathrm{Au}^{\prime \prime \prime} \mathrm{ClBr}\right)_{2}\right)_{2}$ & 4.01 & 2.68 & 86.1 & 31 \\
\hline
\end{tabular}

suggesting the presence of a magnetic interaction between adjacent pairs of gold atoms (33).

\section{Gold(V)}

Mössbauer data were valuable in characterizing the unusually high oxidation state of $+\mathrm{V}$ for gold in the compounds $\mathrm{Cs}\left[\mathrm{AuF}_{6}\right], \mathrm{XeF}_{5}\left[\mathrm{AuF}_{6}\right]$ and $\mathrm{Xe}_{2} \mathrm{~F}_{11}\left[\mathrm{AuF}_{6}\right]$ (34). The IS of these compounds $(3.60,3.53$ and $3.49 \mathrm{~mm} / \mathrm{s}$, respectively) are much higher than for any of the other gold halides or halide complexes, for example 1.61 to $1.95 \mathrm{~mm} / \mathrm{s}$ for $\left[\mathrm{AuX}_{2}\right]^{-}(3,4,35)$ and 1.26 to $2.30 \mathrm{~mm} / \mathrm{s}$ for $\left[\mathrm{AuX}_{4}\right]^{-}$ $(4,8)$. The best comparison would be with other fluorocomplexes. No fluoride is known for gold(I), but the range of IS reported for $\left[\mathrm{AuF}_{4}\right]^{-}$is 1.26 to $1.90 \mathrm{~mm} / \mathrm{s}(7,8)$. The dramatic increase shown by $\left[\mathrm{AuF}_{6}\right]-$ is the result of decreased shielding of the nucleus due to the removal of two $5 d$ electrons.

All the $\left[\mathrm{AuF}_{6}\right]^{-}$salts give single-line spectra with unbroadened lines, so that the QS is effectively zero. This is consistent with the $d^{b}$ configuration and the octahedral stereochemistry. Even in the $\left[\mathrm{Xe}_{2} \mathrm{~F}_{1}\right]+$ salt, the $\mathrm{Au}-\mathrm{F}$ distances are very similar for the terminal $\mathrm{Au}-\mathrm{F}$ and bridging Au-F-Xe units.

\section{Cluster Compounds}

Several types of gold cluster compounds have been recognized in recent years, containing groups of five, six, eight, nine, or eleven gold atoms. In the higher members 

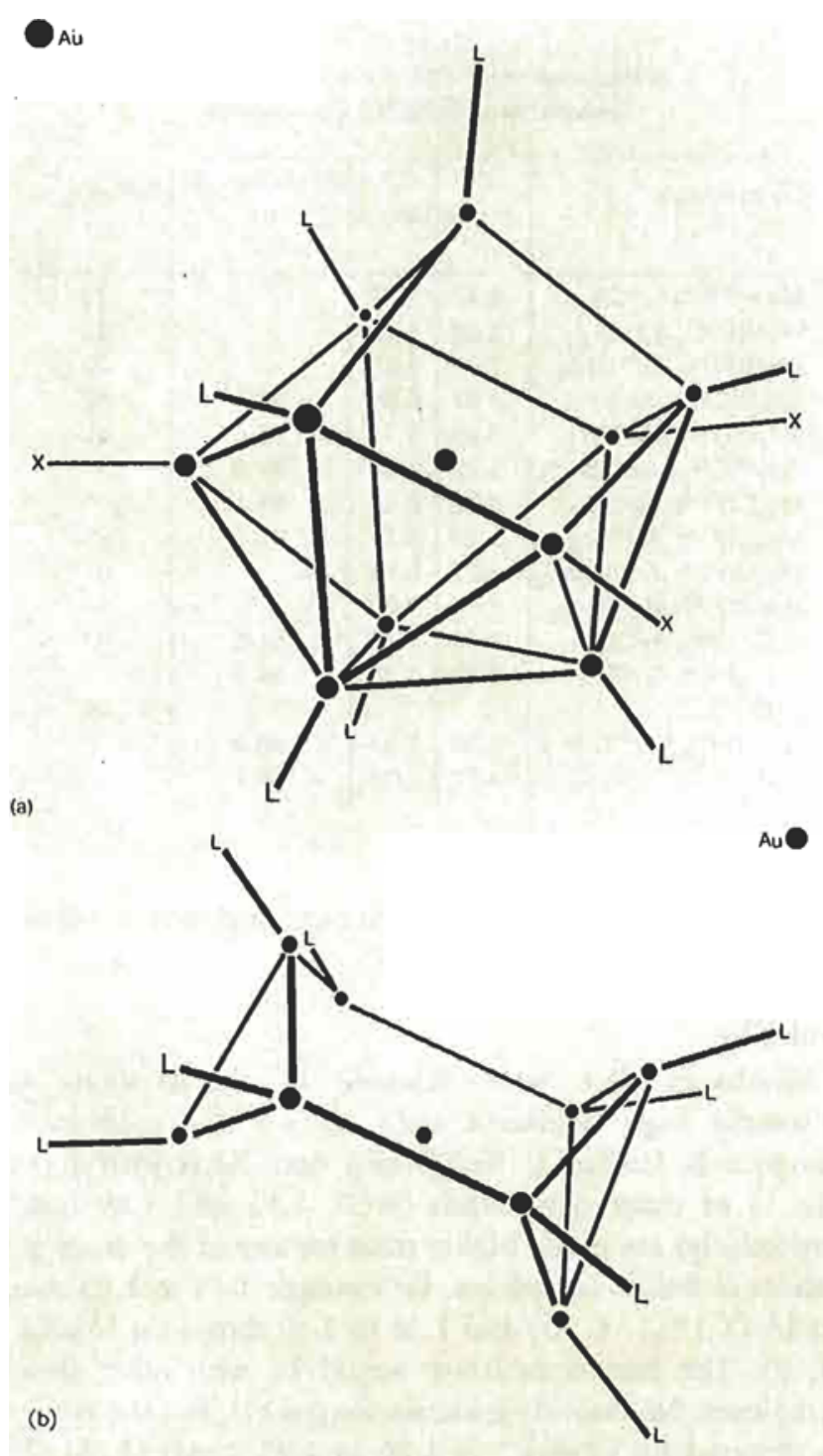

Fig. 9 The shapes of cluster compounds containing (a) $\mathrm{Au}_{11}$ and (b) $\mathrm{Au}_{9}$ units. For the sake of clarity, bonds to the central gold atoms are omitted. After $(38,39)$

( $\mathrm{n}=9$ or more), a central gold atom is surrounded by, and presumably bonded to, the remainder; each peripheral atom is also bonded to a phosphine ligand or an anion, and the Au-Au-L bond angles are close to $180^{\circ}$. The structures of compounds with $\mathrm{n}=9$ and 11 are shown in Figure 9.

Mössbauer spectra have been obtained for several cluster compounds of the $\mathrm{Au}_{9}$ - and $\mathrm{Au}_{11}$-types $(36,37)$. It is usually possible to distinguish separate doublets for the gold atoms bound to the phosphine and to the anion, together with a singlet for the central gold atom (Table VIII). The parameters for the phosphine-bound atoms are all closely similar, but those for the anion-bonded atoms vary in a similar way to those for more conventional compounds, increasing in the order $\mathrm{X}=\mathrm{Cl}$ through $\mathrm{SCN}$ to $\mathrm{CN}$. The replacement of a coordinated anion by a phosphine, for example in the conversion of the compound $\mathrm{Au}_{11}\left(\mathrm{PPh}_{3}\right)_{7}(\mathrm{SCN})_{3}$ into $\left[\mathrm{Au}_{11}\left(\mathrm{PPh}_{3}\right)_{8}(\mathrm{SCN})_{2}\right] \mathrm{PF}_{6}$, gives an appropriate change in the relative intensities of the doublets.

The close similarity of the spectra of the complexes of general formula $A u_{9} L_{8} X_{3}$ indicates that the anions are not coordinated. Treatment of this type of compound $\left(\mathrm{X}=\mathrm{PF}_{6}\right)$ with additional ligands gives a compound of formula $\left[\mathrm{Au}_{9} \mathrm{~L}_{10}\right] \mathrm{PF}_{6}$, the Mössbauer spectrum of which is almost identical to that of the starting material, but the central gold atom shows a slight increase in IS (37). The phosphorus-31 NMR spectrum shows a signal ratio of $8 / 2$ and the minor component undergoes rapid exchange with the free ligand. It was suggested that the two additional ligands are bound to the central gold at $\mathrm{n}$, which then attains ten-coordination similar to that in the $A u_{11}$ clusters, and this appears to be structurally feasible.

In all these compounds, the central gold atom shows a singlet spectrum. Presumably, eight- or ten-coordination approaches spherical symmetry sufficiently closely to ensure that the EFG is very small. The parameters for the peripheral atoms are close to those for linear gold(I) systems, which is consistent with the observation $(38,39)$ that the Au-Au bond distances to the central atom (approximately $270 \mathrm{pm}$ ) are generally shorter than those between peripheral atoms ( 275 to $319 \mathrm{pm}$ ). The parameters for the phosphine-bound gold atoms lie on the low IS side of the QS-IS correlation of Figure $5 c$, that is, in a direction indicative of a coordination number higher than two.

Inspection of Figure 9 shows three types of phosphinebound gold atoms: basal, equatorial and apical. Attempts have therefore been made to fit the spectra with four doublets and one singlet (36). Unfortunately, the line width is such that a fit can be made only by severely constraining the parameters, and even then there is ambiguity in the assignment of closely overlapped lines.

\section{Applications}

In the above sections, the systematic variation of the gold-197 Mössbauer parameters with the oxidation state of the metal, and the number and nature of the ligands, has been exemplified. In this section, the utility of the technique is illustrated by applications in which the Mössbauer data have been invaluable in the characterization of the compounds, or in choosing between alternative structures. 


\section{Gold(I) Thiolates}

Several compounds of the type AuSR have been used for many years as drugs for the treatment of rheumatoid arthritis. Examples are those in which $\mathrm{SR}$ is a thiomalate or a thioglucose group (40). Despite the importance of this application, the structures of these compounds, or even of those in which $\mathrm{SR}$ is a simple thiolate group, are not known in any detail. The general coordination chemistry of gold(I) suggests that the metal should be at least twocoordinate and that the compounds should be polymeric. The compounds have not been crystallized, and X-ray data are not available, but an analogous silver compound, $\mathrm{AgSC}_{6} \mathrm{H}_{11}$, does have a polymeric structure involving both two- and three-coordinate silver (41).

The Mössbauer spectra of the pharmacological compounds are very similar to those with simpler SR groups and lie in the range characteristic of two-coordinate gold(I) (5). The spectrum of MYOCRYSIN (sodium gold thiomalate) is shown in Figure 2. The parameters are close to those for complexes in which gold(I) is known to be coordinated by two S-donor ligands (Table IX), and the presence of three-coordinate gold seems unlikely. The thiolates must therefore have polymeric structures, $-S(R)-A u-S(R)-A u-$, with linear twocoordination at the gold. The different degrees of polymerization which are implied by the wide range of solubilities experienced by the compounds are not reflected in the Mössbauer spectra, but the latter do vary systematically with the nature of the $R$ group (13).

\section{An Apparently Three-Coordinate Complex}

During a search for gold(I) compounds with coordination numbers greater than two, a compound, the analysis of which was consistent with the formula $\left[\mathrm{Au}\left(\mathrm{AsPh}_{3}\right)_{3}\right] \mathrm{NO}_{3}$, was isolated (6). The Mössbauer spectrum gave the expected doublet, but the intensities of the two lines were very different, in a ratio of about $3 / 1$. The parameters of the doublet were consistent with two-coordination, fitting neatly into the QS-IS correlation for other gold(I)-arsine complexes. The position of the more intense peak was close to that of the single peak of the four-coordinate $\left[\mathrm{Au}\left(\mathrm{AsPh}_{3}\right)_{4}\right]_{\mathrm{ClO}}$. It seems that the apparent three-coordinate complex is actually a $1 / 1$ mixture of the bis and tetrakis complexes. Several other gold(I) systems display similar disproportionation (6).
Table VIII

Mössbauer Data for Gold Cluster Compounds, $(\mathrm{mm} / \mathrm{s})$

\begin{tabular}{c|c|c|c|c|c|c}
\multicolumn{2}{c|}{$\begin{array}{c}\text { Central } \\
\text { gold atom }\end{array}$} & \multicolumn{3}{c|}{$\begin{array}{c}\text { Peripheral gold atoms } \\
\text { Au- } L\end{array}$} & \multicolumn{2}{c}{ Au-X } \\
Reference
\end{tabular}

\section{Apparent Gold(II) Complexes}

As previously indicated, many systems which appear from their empirical formulae to contain gold(II) are actually mixed-valence compounds. Distinction between gold(II) and gold(I plus III) systems is readily made from the Mössbauer spectra, since the former should show only a single doublet while the latter should show two. An example of this has already been given in Table VII, where the products of

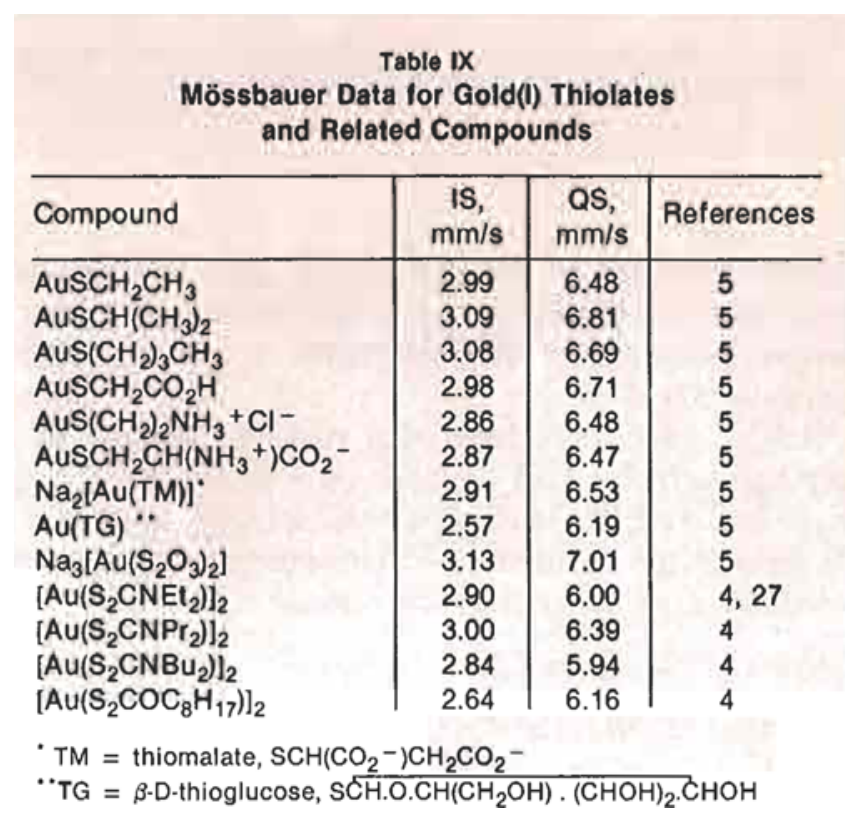




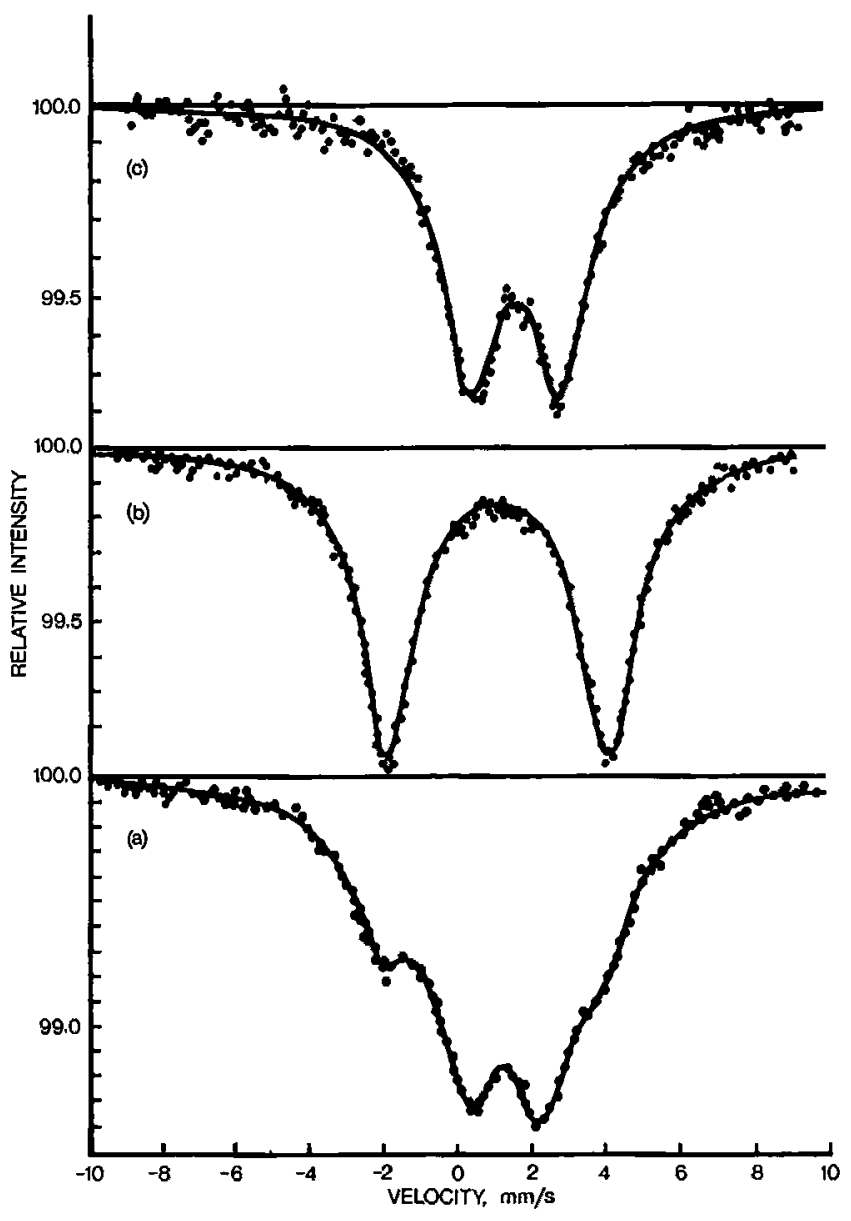

Fig. 10 Mössbauer spectra of (a) $\operatorname{AuBr}_{2}(L)$, (b) $\operatorname{AuBr}(L)$, and (c) $\mathrm{AuBr}_{3}(\mathrm{~L})$, where $\mathrm{L}=\mathrm{S}\left(\mathrm{CH}_{2} \mathrm{Ph}\right)_{2}$, Redrawn with permission from (35)

bromine-oxidation of $\mathrm{H}_{2} \mathrm{C}\left(\mathrm{PPh}_{2} \mathrm{AuCl}\right)_{2}$ gave two doublets characteristic of gold(I) and gold(III), whereas that from a similar oxidation of $\mathrm{Me}_{2} \mathrm{C}\left(\mathrm{PPh}_{2} \mathrm{AuCl}\right)_{2}$ gave a simple spectrum (31).

Similar observations have been made for compounds of empirical formulae $\mathrm{Au}\left(\mathrm{S}_{2} \mathrm{CNR}_{2}\right) \mathrm{X} \quad(\mathrm{R}=\mathrm{Pr}, \mathrm{Bu}, \mathrm{Ph} ; \mathrm{X}=\mathrm{Cl}$, $\mathrm{Br}, \mathrm{I})(35), \mathrm{AuX}_{2}\left[\mathrm{~S}\left(\mathrm{CH}_{2} \mathrm{Ph}\right)_{2}\right](\mathrm{X}=\mathrm{Cl}, \mathrm{Br})(35)$, and $\mathrm{CsAuCl}_{3}$ (7). In each, the true formula is double the empirical one and two different oxidation states are present:

$$
\begin{aligned}
& {\left[\mathrm{Au}^{\mathrm{III}}\left(\mathrm{S}_{2} \mathrm{CNR}_{2}\right)_{2}\right]\left[\mathrm{AuIX}_{2}\right],} \\
& \mathrm{Au} \mathrm{X}\left[\mathrm{S}\left(\mathrm{CH}_{2} \mathrm{Ph}\right)_{2}\right] \cdot \mathrm{Au}^{\mathrm{III} \mathrm{X}_{3}}\left[\mathrm{~S}\left(\mathrm{CH}_{2} \mathrm{Ph}\right)_{2}\right] \text {, } \\
& \text { and } \mathrm{Cs}_{2}\left[\mathrm{Au}^{\mathrm{I} C l} \mathrm{Cl}_{2}\right]\left[\mathrm{Au}^{\mathrm{III}} \mathrm{Cl}_{4}\right] \text {. }
\end{aligned}
$$

The spectrum of the second of these is compared with those of the component gold(I) and gold(III) compounds in Figure 10. It should be noted that in the mixed-valence compounds, the gold(I) component appears with lower intensity than gold(III); this is principally a reflection of the greater mass of the gold(III)-containing unit, which therefore has a larger recoil-free fraction (35).

\section{Gold(III) Schiff-Base Derivatives}

Ligands of type 4, (abbreviated SB and shown below,) give gold(III) complexes of composition $\mathrm{Au}(\mathrm{SB}) \mathrm{Cl}_{2}$ (42):<smiles>[R]N=Cc1ccccc1[O-]</smiles>

However, their Mössbauer spectra are not the simple doublets which would be expected for this formulation (Figure 11). A good fit is obtained with two doublets, one with larger IS and QS than the other, both in the normal range for gold(III). The compounds give solutions which conduct electricity, and they are probably dimeric and ionic, with gold in both the cation and anion: $\left[\mathrm{Au}(\mathrm{SB})_{2}\right]\left[\mathrm{AuCl}_{4}\right]$. The intensities of the two doublets are again dissimilar; this is probably also a measure of the large difference in mass between the two ions.

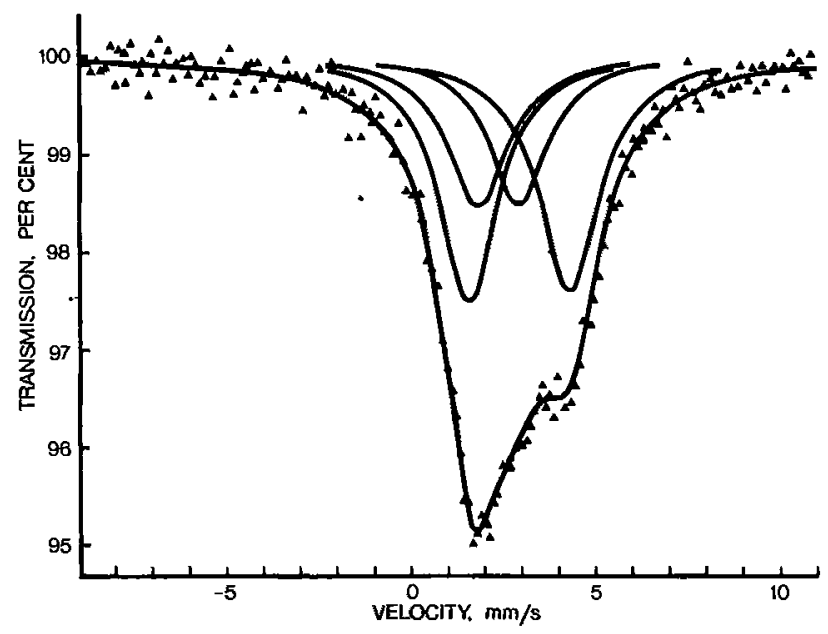

Fig. 11 Mössbauer spectrum of $\left[\mathrm{Au}(\mathrm{SB})_{2}\right]\left[\mathrm{AuCl}_{4}\right]$ where $\mathrm{SB}=$ $2-\mathrm{C}_{6} \mathrm{H}_{4}\left(\mathrm{O}^{-}\right)\left(\mathrm{CH}: \mathrm{NC}_{3} \mathrm{H}_{7}\right)$. The fitted spectrum and the four component lines are shown 


\section{Conclusion}

Mössbauer spectroscopy clearly has great utility in the characterization of gold compounds. The two major oxidation states can be readily distinguished, and intelligent guesses can be made about the identities of the ligand donor atoms and their number. The major limitation of the technique is the relatively large natural line-width, which limits the resolution. Overlapping peaks closer than about $0.7 \mathrm{~mm} / \mathrm{s}$ are not resolved, and appear as a broadened single peak. There is, therefore, the possibility that closely similar, but non-identical, sites within one sample would not be detected (see the section on cluster compounds). Fortunately, in most cases where this is likely, the two QS values are different, and it is unusual for both pairs of peaks to overlap.

As the final section above has shown, Mössbauer spectra often yield information which would be difficult to obtain by other techniques, short of a full $\mathrm{X}$-ray investigation, and further important applications are anticipated.

\section{References}

1 N.N Greenwood and T.C. Gibb, 'Mössbauer Spectroscopy', Chapman and Hall, London, 1971

T.C. Gibb, 'Principles of Mössbauer Spectroscopy', Chapman and Hall, London, 1976

G.M. Bancroft, 'Mössbauer Spectroscopy', McGraw Hill, New York, 1974

2 M.P.A. Viegers and J.M. Trooster, Nucl. Instrum. Methods, 1974, 118, 257-258

3 P.G. Jones, A.G. Maddock, M.J. Mays, M.M. Muir and A.F. Williams, J.Chem.Soc. Dalton Trans., 1977, 1434-1439

4 J.M. Trooster and M.P.A. Viegers, unpublished data

M.P.A. Viegers, Ph.D. Thesis, Catholic University of Nijmegen, Nethcrlands, 1976

Data are quoted by P. Gütlich, R. Link and A. Trautwein, 'Mössbauer Spectroscopy and Transition Metal Chemistry', Springer-Verlag, Berlin, 1978

5 K. Brown, R.V. Parish and C.A. McAuliffe, J. Am. Chem. Soc., 1981, $103,4943-4945$

6 R.V. Parish, O. Parcy and C.A. McAuliffe, J. Chem. Soc. Dalion Trans, 1981,2098

7 M.O. Faltens and D.A. Shirlcy, J. Chem. Phys., 1970, 53, 4249-4264

8 H.D. Bartunik, W. Potzel, R.L. Mössbaucr and G. Kaindl, Z. Pbys. 1970, 240, 1-16

9 W. Potzel and G.J. Perlow, Phys. Rev. Lett., 1972, 29, 910

10 E. Baggio-Saitovich, U. Wagner, F.E. Wagner and J. Danon, in 'Proc. Int. Conf. Mössbauer Spectrosc.' Cracow, 1975, Vol. 1, p. 223

11 C.A. McAuliffe, R.V. Parish and P.D. Randall, J. Chem. Soc. Dalton Trans. , 1977, 1426-1430

12 R.V. Parish and J.D. Rush, Chem. Pbys, Lett., 1979, 63, 37.39

13 A.K.H. Al-Sa'ady, K. Brown, R.V. Parish and C.A. McAuliffe, in 'Proc. Int. Conf. Applications Mössbauer Spectrosc.', Jaipur, India, 1981 , in press

14 G. van Koten and J.G. Noltes, J. Organomet. Chem. 1979, 174, 367.387

15 M.J. Mays and P.A. Vergnano, J. Chem. Soc. Dalton Trans., 1979, 1112-1115

16 C.B. Colburn, W.E. Hill, C.A. McAuliffe and R.V. Parish, J. Chem. Soc. Chem. Commun., 1979, 218-219

17 E.L. Muetterties and C.W. Álegranti, J. Am. Chem. Soc., 1970, 92, 4114-4115

18 E.L. Muctterties, W.G. Peet, P.A. Wegner and C.W. Alegranti, Inorg. Chem. 1970, 9, 2447-2451

19 G.C.H. Jones, P.G. Jones, A.G. Maddock, M.J. Mays, P.A. Vergnano and A.F. Williams, J. Chem. Soc. Dalton Trans., 1977, 1440-1443

20 H. Schmidbaur, F.E. Wagner and A. Wohlleben-Hammer, Chem. Ber., 1979, 112, 496-500

21 N.C. Baenziger, K.M. Dittmore and J.R. Doyle, Inorg. Chem., 1974, $13,805-810$

22 J. Strähle and G. Beindorf, quoted by P.G. Jones, Gold Bull. , 1981, 14, 102

23 F. Klanberg, E.L. Muetterties and L.J. Guggenberger, Inorg. Chem., $1968,7,2272-2278$

24 P.G. Jones, J. Chem. Soc. Chem. Commun., 1980, 1031-1033

25 W. Clegg, Acta Crystallogr., 1976, B32, 2712-2714

26 R.V. Parish and P.J. Rowbotham, J. Chem. Soc. Dalton Trans., 1973, $37-41$

27 R.V. Parish and J.D. Rush, unpublished results

28 A. Johnson and R.J. Puddephatt, J. Chem. Soc. Dalton Trans., 1978, 980-985

29 H. Prosser, F.E. Wagner, G. Wortmann, G.M. Kalvius and R Wappling, Hyperfine Interactions, 1975, 1, 25-32

30 H.D. Bartunik, W.F. Holzapfel and R.L. Mössbauer, Phys, Lett., 1970, A33, 469-471

31 H. Schmidbaur, A. Wohlleben, F.E. Wagner, D.F. van der Vondel and G.P. van der Kelen, Chem. Ber., 1977, 110, 2758

32 H. Schmidbaur, J,R. Mandl, F,E. Wagner, D.F. van der Vondel and G.P. van der Kelen, J. Chem. Soc. Chem. Commun., 1976, 170-172

33 H. van Kempen, J.A.A.J. Pereboom and M.P.A. Viegers, in 'Proc. 14th Int. Conf. Low-Temp. Phys,', edited by M. Krusius and M. Vuoria, North Holland, New York, 1975, Vol. 4, p. 372

34 G. Kaindl, K. Leary and N. Bartlett, J. Chem. Phys., 1973, 59, 5050-5054

35 T.P.A. Viegers, J.M. Trooster, P. Bouten and T.P. Rit, J. Chem. Soc. Dalton Trans., 1977, 2074-2080

36 F.A. Vollenbroek, P.C.P. Bouten, J.M. Trooster, J.P. van den Berg and J.J. Bour, Inorg. Chem. 1978, 17, 1345

37 F.A. Vollenbroek, J.J. Bour, J.M. Trooster and J.W.A. van der Velden, J. Chem. Soc, Chem. Commun., 1978, 907-909

38 P. Bellon, M. Manassero and M. Sansoni, J. Chem. Soc. Dalton Trans., $1972,1481-1487$

39 M. Manassero, L. Naldini and M. Sansoni, J. Chem. Soc. Chem. Commun., 1979, 385-386

40 C.F. Shaw, Inorg. Perspect. Biol. Med., 1978, 2, 287-355

41 S.H. Hong, A. Olin and R. Hesse, Acta Chem. Scand., 1975, A29, 583.589

42 K. Brown, C.A. McAuliffe and R.V. Parish, unpublished data 